\title{
Strategi Pengembangan Pantai Pengklik Sebagai Tujuan Wisata Alternatif Di Kabupaten Bantul
}

\author{
Iputu Hardani \\ Sekolah Tinggi Pariwisata Ampta Yogyakarta \\ E-mail: iputu.hardani@gmail.com
}

\begin{abstract}
Bantul Regency is one of 5 (five) districts in Yogyakarta. Tourism located in Bantul is currently growing rapidly, one of the tourist destinations are much in demand by tourists when traveling to Bantul is a beach tour. However, many tourists who visit the beaches are famous only while a lot of beach tourism that has not been famous that basically has the same charm with the beaches. One of them is Pengklik Beach located in Bantul Regency. Therefore the researchers are interested to conduct research with the title "Strategy Development Pengklik Beach As Alternative Tourism Destination In Bantul". The research method used in this research is using qualitative method. The collecting technique used is interview, observation, and documentation, while in data analysis method the researcher uses data reduction, data display, conclusion and also using SWOT analysis method. The research results show that the Department of Tourism so far only acts as a companion, has not seen the efforts made by the Department of Tourism in terms of coastal development, especially for infrastructure development in Pengklik Beach, the existing infrastructure built there by the beach manager whose funds derived from tourism conscious from central government, development. From the results of socialization analysis of the government is very influential for the progress tourism conscious group existing there, the promotion made from the tourism conscious group can be one way for Pengklik Beach can be an alternative tourism destination in Bantul and increase tourist visits. In addition to optimizing the existing attractions in Pengklik Beach can be a special attraction so that the level of tourist visits can increase and become alternative destination of tourism.
\end{abstract}

Keywords: Strategy, Development, Pengklik Beach

Abstrak - Kabupaten Bantul adalah satu dari 5 (lima) kabupaten di Yogyakarta. Pariwisata yang terletak di Bantul saat ini berkembang pesat, salah satu tujuan wisata yang banyak diminati oleh wisatawan ketika bepergian ke Bantul adalah wisata pantai. Namun, banyak wisatawan yang mengunjungi pantai hanya terkenal sementara banyak wisata pantai yang belum terkenal yang pada dasarnya memiliki pesona yang sama dengan pantai. Salah satunya adalah Pantai Pengklik yang terletak di Kabupaten Bantul. Oleh karena itu peneliti tertarik untuk melakukan penelitian dengan judul "Strategi Pengembangan Pantai Pengklik Sebagai Destinasi Wisata Alternatif Di Bantul". Metode penelitian yang digunakan dalam penelitian ini adalah menggunakan metode kualitatif. Teknik pengumpulan yang digunakan adalah wawancara, observasi, dan dokumentasi, sedangkan dalam metode analisis data peneliti menggunakan reduksi data, penyajian data, penarikan kesimpulan dan juga menggunakan metode analisis SWOT. Hasil penelitian menunjukkan bahwa Departemen Pariwisata sejauh ini hanya bertindak sebagai pendamping, belum melihat upaya yang dilakukan oleh Departemen Pariwisata dalam hal pengembangan pantai, terutama untuk pembangunan infrastruktur di Pantai Pengklik, infrastruktur yang ada dibangun di tepi pantai. Manajer yang dana berasal dari pariwisata sadar dari pemerintah pusat, pengembangan. Dari hasil analisis sosialisasi pemerintah sangat berpengaruh terhadap kemajuan kelompok sadar pariwisata yang ada di sana, promosi yang dilakukan oleh kelompok sadar wisata dapat menjadi salah satu cara agar Pantai Pengklik dapat menjadi alternatif tujuan wisata di Bantul dan meningkatkan kunjungan wisatawan. Selain mengoptimalkan objek wisata yang ada di Pantai Pengklik dapat menjadi daya tarik khusus sehingga tingkat kunjungan wisatawan dapat meningkat dan menjadi alternatif tujuan wisata.

Kata kunci: Strategi, Pengembangan, Pantai Pengklik

\subsection{Latar Belakang}

Pantai Pengklik merupakan salah satu pantai yang ada di Bantul. Pantai yang memiliki keindahan alam ini masih sangat terjaga kealamiannya, karena pantai ini belum banyak diketahui. Air lautnya yang biru bersih, dan terdapat pertemuan arus air tawar dengan air asin sehingga menyajikan pemandangan alam hamparan lautan yang menakjubkan. Di Pantai Pengklik juga terdapat gazebo yang dapat digunakan untuk beristirahat sambil menikmati pemandangan pantai, selain itu juga 
terdapat warung makan, toilet, dan juga tempat parkir bagi para pengunjung.

Pantai Pengklik ini dapat menjadi salah satu wisata alternatif bagi wisatawan yang ingin berkunjung ke pantai saat musim liburan ataupun hari-hari biasa untuk hanya sekedar ingin menikmati keindahan pantai dengan hamparan keindahan alam dan lautan yang luas. Selain itu juga pantai ini bisa digunakan untuk spot memancing karena berbatasan langsung dengan perairan air tawar.

Kelebihan dari Pantai Pengklik adalah ukuran garis pantai yang tidak terlalu panjang serta berdekatan dengan arus tawar dengan arus air asin. Pantai Pengklik juga merupakan salah satu pantai di Bantul dimana wisatawan dapat melihat penyu hijau maupun penyu sisik pada musim- musim tertentu. Selain itu daya tarik lainnya yaitu laguna serta para pengunjung bisa menikmati keindahan wisata Pengklik dengan menaiki perahu berbayar RP $10.000,00$. Jika sudah lelah berkeliling, pengunjung bisa beristirahat di gardu pandang yang berada di tengah kawasan Pantai Samas sambil menikmati berbagai jajanan dan kuliner Pantai Samas.

Pantai Pengklik pada dasarnya memiliki daya tarik yang sama dengan pantai-pantai lain yang ada di Bantul, akan tetapi dari segi aksesibilitas Pantai Pengklik terhubung dengan jalur lintas selatan sehingga lebih mudah dijangkau oleh wisatawan yang akan berkunjung ke pantai. Namun masih belum aja jalur khusus bagi para wisatawan yang berkunjung ke Pantai Pengklik menggunakan bus.

Tujuan dari penelitian untuk mengetahui sejauh mana peran pemerintah dalam keikutsertaan pengembangan Pantai Pengklik dan untuk mengetahui bagaimana strategi yang dilakukan Dinas Pariwisata dan Pengelola untuk pengembangan Pantai Pengklik. Dari kasus tersebut peneliti tertarik untuk meneliti dengan judul "Strategi Pengembangan Pantai Pengklik sebagai Tujuan Wisata Alternatif Di Kabupaten Bantul”.

\subsection{Kajian Pustaka}

\subsubsection{Pariwisata}

Menurut Undang-undang $\mathrm{RI}$ No 10 Tahun 2009 tentang kepariwisataan menyebutkan bahwa "berbagai macam kegiatan wisata dan didukung berbagai fasilitas serta layanan yang disediakan oleh masyarakat pengusaha, pemerintah, dan pemerintah daerah."

\subsubsection{Strategi}

Istilah strategi sudah menjadi istilah yang sering digunakan oleh masyarakat untuk menggambarkan berbagai makna seperti suatu rencana, taktik atau cara untuk mencapai apa yang diinginkan. Strategi pada hakikatnya adalah perencanaan (planning) dan manajemen (management) untuk mencapai suatu tujuan. Tetapi, untuk mencapai tujuan tersebut, strategi tidak berfungsi sebagai peta jalan yang hanya menunjukkan arah saja, melainkan harus mampu menunjukkan bagaimana taktik operasionalnya. (Effendy, 2007:32).

\subsubsection{Analisis SWOT}

SWOT adalah singkatan dari Strenghts (Kekuatan), Weaknesess (Kelemahan), Opportunities (Peluang) dan Threats (Ancaman). dalam hal ini Strenghts dan Weaknesess termasuk dalam faktor lingkungan internal sebuah destinasi wisata sedangkan Opportunities dan Threats faktor eksternal sebuah destinasi dimana analisi SWOT tersebut adalah membandingkan faktor internal dan eksternal suatu destinasi tersebut. (Rangkuti 2015 : 20)

\subsubsection{Pengembangan Pariwisata}

Dalam perencanaannya pengembangan daya tarik wisata harus memperhatikan lima tahap proses perencanaan pariwisata (A. Yoeti, 2008:53) yaitu melakukan inventarisasi mengenai semua fasilitas yang tersedia dan potensi yang dimiliki, menaksir pasaran pariwisata dan mencoba melakukan proyeksi arus kedatangan wisatawan pada masa yang akan datang, memperhatikan di mana terdapat permintaan yang lebih besar dari pada persediaan atau penawaran, melakukan penelitian kemungkinan perlunya penanaman modal baik negeri maupun asing, melakukan perlindungan terhadap kekayaan alam yang dimiliki dan memelihara warisan budaya bangsa serta adat istiadat suatu bangsa yang ada.

\subsection{Metode Penelitian}

Metode yang digunakan dalam penelitian ini adalah metode Kualitatif. Menurut Sugiyono (2009:15) penelitian kualitatif adalah suatu metode penelitian yang berlandaskan pada filsafat postpositivisme, digunakan untuk meneliti pada kondisi objek yang alamiah dimana peneliti adalah sebagai instrumen kunci, pengambilan sampel sumber data dilakukan secara purposive, teknik pengumpulan dengan triangulasi, analsis data bersifat induktif/kualitatif. Penelitian kualitatif bertumpu pada latar belakang alamiah, memposisikan manusia sebagai alat penelitian, melakukan analisis secara induktif, lebih mementingkan proses dari pada hasil serta hasil penelitian yang dilakukan disepakati oleh peneliti dan subjek penelitian. 


\subsubsection{Lokasi Penelitian}

Lokasi penelitian ini dilakukan di Pantai Pengklik, Desa Srigading, Kecamatan Sanden, Kabupaten Bantul, Yogyakarta. Peneliti memilih lokasi di Bantul karena sekarang ini Bantul sedang berkembang pesat dalam hal pariwisata, akan tetapi untuk aksesibilitas wisata di Bantul masih kurang maksimal ,antara lain kurangnya penunjuk jalan untuk sampai ke tempat wisata, salah satunya yaitu obyek wisata Pantai Pengklik.

\subsubsection{Teknik Pengumpulan Data}

Penelitian ini menggunakan teknik pengumpulan data diantaranya observasi, wawancara, dan dokumentasi.

\subsubsection{Metode Analisis Data}

Penelitian ini menggunakan metode analisis yang berupa reduksi data, penyajian data, penarikan kesimpulan serta menggunakan metode analisis SWOT.

\subsection{Hasil Penelitian Dan Pembahasan

4.1.1. Peran Dinas Pariwisata Terkait
Dengan Pengembangan Pantai
Pengklik \\ Dalam hal ini peran pemerintah} sangatlah berpengaruh dalam proses pengembangan suatu destinasi wisata terlebih lagi jika destinasi wisata tersebut termasuk destinasi wisata yang masih belum terlalu terkenal. Berdasarkan penelitian sebelumnya terhadap tingkat kunjungan wisatawan domestik periode tahun 2011-2015 menunjukkan bahwa Pantai Parangtritis menjadi salah satu pantai Favorit dengan jumlah pengunjung diatas 1 juta wisatawan pertahun, sedangkan candi-candi kecil serta petilasan bersejarah menjadi objek wisata yang paling sedikit dikunjungi wisatawan (Yulianto, 2017).

Di Pantai Pengklik ini peran pemerintah atau Dinas Pariwisata untuk saat ini berperan sebagai pendamping. Saat ini peran pemeritah khususnya Dinas Pariwisata terhadap pengembangan Pantai Pengklik bisa dikatakan belum terlihat dari segi pembangunan sarana dan prasarana di kawasan Pantai Pengklik, karena di Pantai Pengklik mulai dari perbaikan jalan hingga sarana dan prasarana yang ada di sana dibangun oleh dana iuran dari pokdarwis dan juga swadana dari masyarakat setempat. Namun beberapa tahun terakhir ini pihak Dinas Pariwisata Kabupaten Bantul memberikan pendampingan dan pembangunan beberapa sarana prasarana berupa pondok-pondok untuk menjual makanan. Sejauh ini Dinas Pariwisata juga sudah ada kontribusi dalam hal penarikan retribusi kawasan Pantai Pengklik. Di Pantai Pengklik wisatawan yang hendak berkunjung harus membayar tiket masuk sebesar Rp. 5000,- per orang, baik itu dewasa maupun anak kecil. Dalam hal penarikan retribusi, sebenarnya pemerintah khususnya Dinas Pariwisata sudah memiliki kebijakan atau Perda yang mengharuskan bahwa setiap destinasi pariwisata yang ada di Kabupaten Bantul setidaknya sudah harus ada penarikan retribusi, dan dana yang dihasilkan dari penarikan retribusi tersebut nantinya akan digunakan sebagai penambahan amenitas di kawasan Pantai Pengklik.

Meskipun sudah ada retribusi akan tetapi dampak dengan adanya retribusi tersebut belum terlihat secara signifikan untuk pembangunan Pantai Pengklik. Strategi yang dilakukan untuk pengembangan Pantai Pengklik yaitu

1. Dinas Pariwisata

Pemerintah sudah mempunyai rencana pengembangan pantai di tahun 2019 yaitu dengan membangun sarana prasarana guna menunjang pariwisata yang ada disana sesuai dengan RIPARDA Dinas Pariwisata diantaranya, yaitu:

a. Pembangunan Gazebo

Untuk rencana pengembangan Dinas Pariwisata Bantul juga akan menambah fasilitas yaitu berupa adanya pembangunan gazebo di kawasan pantai

b. Pelebaran Jalan

Pemerintah juga merencanakan adanya pelebaran jalan untuk kawasan Pantai Pengklik mengingat sempitnya akses masuk ke kawasan pantai, terlebih lagi jika wisatawan berkunjung kesana menggunakan bus.

2. Pengelola/ Pokdarwis Pantai Pengklik

Selain dari Dinas Pariwisata pengembangan yang ada di kawasan Pantai Pengklik juga tak lepas dari peran Pokdarwis. Sejak dibukanya Pantai Pengklik sebagai destinasi wisata pada tahun 2015, Pokdarwis yang ada disana sudah melakukan strategi pengembangan pantai yaitu dengan membangun beberapa sarana dan prasarana seperti Pembangunan Amenitas. Amenitas yang ada di Pantai Pengklik seperti toilet, mushola, lahan parkir dan warung makan merupakan hasil dari dana iuran pengelola pantai yang dibangun secara gotongroyong pada tahun 2015, sedangkan untuk pembangunan gazebo, Sejauh ini pengelola pantai telah melakukan upaya pengembangan yang cukup besar terhadap Pantai Pengklik, terlebih lagi dalam pembangunan sarana prasarana atau infrastuktur pantai. Harapan akan terkenal dan banyak 
wisatawan yang berkunjung seperti Pantai Parangtritis dan Pantai Samas yang berada dekat dengan Pantai Pengklik adalah salah satu alasan yang membuat pengelola dengan sukarela membangun sarana dan prasarana yang ada disana.

3. Strategi Untuk Pengembangan Pantai Pengklik.

Untuk mengetahui strategi apa yang sebaiknya harus dilakukan dalam pengembangan Pantai Pengklik perlu dilakukan beberapa strategi yang diambil dengan analisis SWOT dan Matrik SWOT, sebagai berikut:

a. Analisis SWOT

1) Strenght / Kekuatan (S)

a) Kriteria tempat yang layak dijadikan tempat wisata karena sudah tersedianya $3 \mathrm{~A}$ (Amenitas, Aksesebilitas, dan Atraksi) meskipun perlu adanya perbaikan atau pengembangan.

b) Masih alaminya pantai sehingga wisatawan merasa nyaman berkunjung ke pantai

c) Terdapat tempat dimana wisatawan dapat melihat penyu yang tidak bisa didapatkan di pantai lainnya pada bulan April sampai September

d) Sudah tersedianya amenitas atau fasilitas yang memadai seperti toilet, mushola, warung makan dan gazebo.

e) Tersedianya lahan parkir yang memadai

2) Weaknesses / Kelemahan (W)

a) Kurangnya papan penunjuk menuju ke obyek wisata Pantai Pengklik

b) Kurangnya sosialisasi antara pemerintah khususnya Dinas Pariwisata kepada pengelola atau Pokdarwis Pantai Pengklik terkait dengan Sapta Pesona

c) Wisatawan yang berkunjung tidak bisa setiap saat melihat hewan penyu

d) Tempat sampah di sekitar area pantai kurang memadai

3) Opportunities / Peluang (O)
a) Dapat menjadi destinasi wisata unggulan di Samas
b) Investor berpeluang mengembangkan kawasan Pantai Pengklik

c) Meningkatkan ekonomi masyarakat sekitar

4) Threats / Ancaman (T)
a) Banyaknya destinasi wisata pantai yang pengembangannya atau pengelolaannya lebih baik dari Pantai Pengklik
b) SDM pengembang wisata Pengklik yang diambil bukan dari masyarakat sekitar
c) Terjadinya penangkapan hewan penyu secara ilegal
d) Masyarakat minim sadar wisata dan sapta pesona

Dari hasil analisis SWOT di dapatkan strategi pengembagan seperti berikut :

1) Analisis Matrik SWOT
a) Strategi SO (Strenght Opportunities) : Strategi yang dibuat dengan memanfaatkan seluruh kekuatan dan memanfaatkan peluang sebesar-besaranya

(1) Membuat tempat atau spot foto untuk wisatwan bisa berfoto untuk melihat penyu tanpa merusak lingkungan dan aman

(2) Membuka lapangan kerja untuk masyarakat sekitar
(3) Mengoptimalkan adanya investor untuk pembangunan homestay dengan memperhatikan kearifan lokal atau budaya sekitar

b) Strategi ST (Strenght Treaths) : Strategi dalam menggunakan kekuatan yang dimiliki untuk mengatasi ancaman

(1) Mengoptimalkan kealamian yang ada di Pantai Pengklik

(2) Membuat papan himbauan bahaya jika berenang

(3) Memberdayakan masyarakat setempat menjadi pegawai bila ada pembangunan di sekitar pantai

(4) Membuat penangkaran penyu dengan sumber daya yang memadai

c) Strategi WO (Weaknesses Opportunities) : Strategi yang diterapkan berdasarkan pemanfaatan peluang yang ada dengan cara 
memimimalkan kelemahan yang ada

(1) Melakukan pelebaran jalan terkait dengan akses masuk kawasan pantai yang masih sempit untuk dilalui kendaraan bus wisatawan yang berkunjung ke pantai

(2) Mengoptimalkan papan petunjuk arah agar wisatawan tidak tersesat

(3) Tempat sampah di sekitar kawasan pantai yang memadai

(4) Bekerjasama dengan investor dalam pengembangan pantai

d) Strategi WT (Weaknesses Treaths) : Strategi yang berusaha meminimalkan kelemahan yang ada serta menghindari ancaman

(1) Sosialisasi pemerintah terkait dengan sadar wisata dan sapta pesona kepada masyarakat sekitar

(2) Mengoptimalkan atraksi wisata yang ada dijadikan sebagai wisata unggulan

(3) Membangun fasilitasfasilitas penunjang pariwisata

\subsection{Kesimpulan Dan Saran}

Dari hasil analisis ini dapat dikesimpulkan adalah sebagai berikut :

1. Peran Dinas Kebudayaan Bantul di Pantai Pengklik sejauh ini hanya berperan sebagai pendamping.

2. Strategi pengembangan yang telah dilakukan oleh Pengelola Pantai diantaranya telah membangun infrastruktur yang ada disana yaitu berupa toilet, warung makan, lahan parkir, gazebo dan perahu untuk atraksi lain.
Adapun saran yang dapat diberikan terhadap pengembangan Pantai Pengklik kedepannya agar tepat sasaran yaitu :

1. Dinas Pariwisata agar segera berkontribusi atau berperan secara nyata dalam hal pengembangan Pantai Pengklik.

2. Dinas Pariwisata agar segera merealisasikan strategi pengembangan untuk Pantai Pengklik yang telah direncanakan, agar Pantai Pengklik dapat menjadi tujuan alternatif bagi wisatawan yang akan berwisata ke Bantul.

3. Dibuatnya tempat penangkaran penyu agar dapat menjadi daya tarik tersendiri untuk Pantai Pengklik sehingga bisa meningkatkan tingkat kunjungan wisatawan dan menjadi alternatif tujuan wisata di Kabupaten Bantul.

4. Dinas Pariwisata dan pengelola melakukan promosi terkait dengan destinasi wisata Pantai Pengklik.

\section{Daftar Pustaka}

[1] Undang-Undang Republik Indonesia No 10 Tahun 2009 Tentang Kepariwisataan

[2] Effendy dan Onong Uchjana. 2007. IImu Komunikasi, Teori dan Praktek. Bandung: Remaja Rosdakarya.

[3] Rangkuti, Freddy. 2015. Analisis SWOT: Teknik Membedah Kasus Bisnis. Jakarta: PT Gramedia Pustaka Utama

[4] Sugiyono. 2009. Metode Penelitian Pendidikan Pendekatan Kuantitatif, Kualitatif, dan $R \& D$. Bandung : Alfabeta.

[5] Yoeti, Oka A. 2008. Perencanaan dan Pengembangan Pariwisata. Jakarta: Pradnya Paramita.

[6] Yulianto, Atun. 2017. Analisis Objek Daya Tarik Wisata Favorit Berdasarkan Jumlah Pengunjung Di Daerah Istimewa Yogyakarta. Jurnal Media Wisata, Volume 15 Nomor 2 November 2017. Yogyakarta : STP AMPTA Yogyakarta. 